\author{
Professor Ionel DUMITRU, PhD \\ E-mail: ionel.dumitru@mk.ase.ro \\ Department of Marketing \\ The Bucharest University of Economic Studies \\ Associate Professor Daniel Adrian GÂRDAN, PhD \\ E-mail: daniel.gardan@uab.ro \\ Associate Professor Carmen Adina PAȘTIU, PhD \\ E-mail: carmen.pastiu@uab.ro \\ Professor Andreea Cipriana MUNTEAN, PhD \\ E-mail: andreea.muntean@uab.ro \\ Department of Business Administration and Marketing \\ "1 Decembrie 1918" University of Alba Iulia \\ Associate Professor Iuliana Petronela GÂRDAN, PhD \\ E-mail: mk.petronela.geangu@spiruharet.ro \\ Department of Economic Sciences \\ Spiru Haret University
}

\title{
ON THE MECHANISM OF THE LABEL PERCEPTION: HOW DOES LABELING CHANGE FOOD PRODUCTS CUSTOMER BEHAVIOR?
}

\begin{abstract}
Food products consumption has certain characteristics that implies the perception of certain risk, behavior that can develop loyalty type patterns, emotional involvement of the consumers, and a specific mechanism for identifying, evaluating and processing information that helps the optimal conduct of the purchasing decision-making process. This paper highlights with the help of a field type research perceptions of Romanian urban consumers about food products labeling and how a relationship can be established between variables regarding purchasing decision-making process for food labeled products. With the help of analysis of the main components, more precisely using the exploratory factor analysis method we have tested a conceptual model, that shows Food products buying decision based on labeling has a direct and positive effect on Food products loyalty based on labeling and respectively Food products labeling Interest having a direct and positive effect upon Food products labeling perception, along with Food products loyalty based on labeling that has a direct positive effect on Food products labeling interest. The findings highlight the fact that supplementary knowledge that consumer can appraise into the form of the food label can reduce the perceived risk and enhance the customer loyalty.

Keywords: food products labeling, perception, buying decision, loyalty.
\end{abstract}

JEL Classification: C02, C11, C45, C46, C63

DOI: 10.24818/18423264/55.2.21.12 
Ionel Dumitru, Daniel Adrian Gârdan, Carmen Adina Paștiu, Andreea Cipriana Muntean, Iuliana Petronela Gârdan

\section{Introduction}

The business environment currently requires a better adaptability from food companies, from the perspective of identifying and maintaining efficient communication channels with different categories of stakeholders, and the need of different brands to clearly differentiate from the competition. The great diversity of food products available on the market has led to an escalation of competition between different brands of producers, increasing the need for differentiation between brands to be based on very clearly communicated attributes.

The postmodern consumers' characteristics, their immediate needs and the buying-consumption behavior imply new ways of optimizing the interaction between consumers and products. Consumers of food products have an increasing need for safety in consumption, safety that involves multiple aspects: the correct identification of the origin of the product, the content of nutrients and active substances, warranty terms, interaction with other products, etc. All these aspects are successfully integrated by the package, altogether with the brand image that can mediate the interaction between products and consumers.

Under the pressure of the need to achieve more and more attractive and more efficient ways of presentation in terms of preserving the quality characteristics of products, packaging and in extenso labeling have evolved constantly and substantially in the last $\mathbf{5 0}$ years. Labeling is thus seen today as a complex effort to synthesize essential product information and ensure a sufficiently creative and differentiated packaging design from the competition, whose essential function is to provide technical details about the producer, the time of production, the technology used, the expiration date, product class, ingredients used etc. (Hemmerling et al, 2015). Labels are currently presented in a multitude of forms, being printed, lithographed, engraved or illustrated, containing product identifiers, adherent to it or joining in one form or another the product.

The labeling process is currently very well regulated both at national level and especially at the European market level. In the last instance, labeling supports the exercise of fundamental rights for consumers - the right to be informed before purchasing a product or service, information that needs to be complete, correct and accurate on the essential characteristics of the products in question.

In this context, the present article propose a research aimed to verify the link between degree of interest about food products labeling, food products labeling perception, food products buying decision and food products loyalty based on labeling.

Therefore, this study makes an important contribution to the understanding of the decisional mechanism underlying modern food products consumer behavior influenced by a multitude of factors that can have also a cultural and educational background. 
On the Mechanism of the Label Perception: How Does Labeling Change Food Products Customer Behavior?

The results of this study also show that the perceived risk associated with consumer decisions can be reduced through the connection of the customer to the specific information provided by food product labels and the buying decisional process developed within the framework of labels perception positively influence the customer propensity towards a loyal type behavior on the long run.

This article is structured as follows: second section presents conceptual approaches to the literature review and the development of the hypothesis; the third section provides the research model and methodology; the next sections describe the empirical results and implications of the discussions. The conclusions of the study are outlined in the final part.

\section{Literature review. Theoretical framework and hypothesis development}

In order to assess the influence that labelling can have upon consumer buying decisions and behaviour, we will take into consideration different aspects implied by the context in which consumers are exposed to the information provided by the food product labels. The starting point is represented by the importance of the labeling issue itself in consumer perception. Within the food products field labels are comprising certain categories of information that are essential to determine the quality of products and the degree of nutritional importance for consumers.

The global framework for food products consumption implies a lot of diversified situations and contexts characterized by the fact that consumers are having different degrees of awareness and involvement regarding labels information. Thereby we can talk about specific consumer groups that are more interested in food labeling issue, such as athletes, consumers having different health conditions or consumers specifically concerned with a healthy lifestyle (Moreira et al, 2019).

In case of food products buying decisions, these are taken nowadays within an information overload environment, majority of consumers in developed countries having a routine choice process in order to economize efforts. The categories of factors that are actually influencing the food products choice can be grouped in categories such as: Psychological factors, extrinsic and intrinsic product characteristics, biological and physiological factors, situational factors and different socio-cultural factors. Among extrinsic product characteristics, label are having a preeminent role (Asioli et al, 2017).

The legibility of labels can vary from country to country, as different standards and visual clues are used in order to encode information on labels, expert type labels having more confidence among customers than the ordinary ones (Rupprecht et al, 2020).

DOI: 10.24818/18423264/55.2.21.12 
Ionel Dumitru, Daniel Adrian Gârdan, Carmen Adina Paştiu, Andreea Cipriana Muntean, Iuliana Petronela Gârdan

Different studies highlight the need to obtain an equilibrium between the degree of complexity of information that is presented on labels and consumers ability to process this information in a proper manner (Campos et al, 2011). Consumers tend to use additional informational clues in order to confirm their expectations when they have limited access to labels information or they are presented with ambiguous information. They can be influenced by informational content of labels itself, marketing campaigns and even restrictions imposed by government (Reveiu et al, 2015).

Within the process of attitudes and behavior formation, consumers have choices affected by information and choice alternatives (Solomon, 2013). The exposure to information means give a specific significance to it, consumers are exposed to labels and the degree of exposure is augmented when consumers are actively searching for label information. Exposure to certain label information is followed by the perception development through the form of the meaning that consumers are attaching to the perceived label information. The new meaning can be integrated in previous knowledge that consumer can have on a certain product and to subjective appreciation (related for example to visual design of the label, the structure of the information itself etc.) Through this process, the label information can be used to make choices - direct or indirect effect or one-time or extended effects. Studies also revealed the fact that perceived quality, behavioral attitude, perceived behavioral control and subjective norm, have significant impacts on consumers' purchase intention (Wang et al, 2020).

Significant changes can be observed in current food consumption behavior. Thus, consumers, in an effort to define and evaluate the quality of food, will evaluate both intrinsic and extrinsic, external characteristics, such as: traceability, geographical origin of the product, geographical indications or certification according to a certain standard (eco, bio, organic etc.) (Ingrassia et al, 2017). This explains a new dimension shown in the interest in labels and the information present in them. Also, today it can be said that by buying and consuming food, consumers express their own cultural orientation, how they relate to society and others, define their identity and also express their position on environmental issues related to agriculture.

Therefore, it is crucial for agri-food producers to provide the consumer with clear and accurate information about the agricultural techniques applied and to use traceability systems to increase consumer confidence in quality products, through their associated credit attributes (Czyżewski et al, 2018). Food labels are therefore a powerful tool for the correct communication of this information, by reconciling information on innovative cultivation techniques, designed to be environmentally friendly and healthy products. Therefore, misalignment of information can be reduced and consumers' perception of the value of the product can be improved.

According to the literature, consumers who are aware of the social and environmental impact of their consumer choices pay more attention to the

DOI: 10.24818/18423264/55.2.21.12 
On the Mechanism of the Label Perception: How Does Labeling Change Food Products Customer Behavior?

information displayed on the label as a tool to reduce the risk associated with their purchase (Galati et al, 2019).

The interest in food labeling is different and nuanced depending on the characteristics of consumers and the context of consumption. It became obvious that consumers are sensitive regarding different combinations of products/data and knowledge regarding food products and the propensity to construct a certain perception on labels depends the degree of exposure and the interest that is intrinsic for some people.

Taking account of all the ideas highlighted above we can issue the first research hypothesis: H1: Food Products Labeling Interest positively affects Food Products Labeling Perception

When food product interest is manifesting, there can be a gap between attitude and behavior. Criteria or factors such as price, quality, comfort and familiarity with the brand are still important, defining for consumer behavior. In the same time, Logos and labeling are often confusing and inappropriate for consumers, causing many of them to lose interest in basic messages.

Access to clear and reliable product information is an important factor in the decision-making process (Türkeş et al, 2020). The benefits of sustainable products are often inadequately communicated to consumers, so that they cannot make informed purchasing decisions in accordance with their budget and/or conscience. Uncertainty will/may lead to the use of social information sources, which means that consumers will look to other people for clues/information about the best solution. One way to provide information is by labeling the product. However, there is still a high contrast between the knowledge and perception of labels and the exact characteristics of food.

Awareness of the informational content of labels is low. It is more useful to spread factual information with the help of labels than to build an image around the label, because actually consumers in general do need transparent and factual information in order to diminish uncertainty.

Uncertainty is great in the food field, because the product can only be experienced before purchase to a very small extent. Thus, labeling becomes a very useful tool to provide consumers with essential information related to quality and an increasingly important attribute for consumers who make purchasing decisions, helping consumers to make informed choices.

It has been found that the gender and eating habits of consumers are significantly related to their food label reading behavior (Kumar and Kapoor, 2017). Thus, young adults (17-30 years of age) are situated within their enhanced autonomy stage, leaving their first family nest and becoming more independent in their buying decisions regarding food products. Other factors such as food crisis, the occurrence of diseases due to unregulated diet and poor food quality have contributed to the growing importance of labels globally (Kumar and Kapoor, 2017). In case of certain products, such as wine, consumers are willing to pay a premium price for "natural" wine, and this choice is positively affected by the

DOI: 10.24818/18423264/55.2.21.12 
Ionel Dumitru, Daniel Adrian Gârdan, Carmen Adina Paștiu, Andreea Cipriana Muntean, Iuliana Petronela Gârdan

importance given to information on the content of the ingredient, the production method and the sensory characteristics included on the wine label, the interest showed for labeling being directly connected with the buying behavior (Galati et al, 2019).

Taking account of all the above we can issue the second hypothesis of the research model (H2): Food Products Labeling Interest positively affects Food Products Buying Decision based on labeling

Consumers decide whether or not to buy based on three main issues: knowledge, attitude and intention. Consumer knowledge is a construction that affects how and what consumers decide to buy. Knowledge of people is affected by the type and quality of information made available to consumers. Advertising, processing, certification and label awareness all play a key role in enriching knowledge. Consumers tend to consider a food product safer if they can assess its high quality. Perceptions about quality are influenced by different characteristics of the product.

Consumers are increasingly interested in health, well-being and the environment, with labeling playing an important role in the size of behavioral control - the intention to develop a certain behavior and attitudes. A study of 1052 New Zealand respondents highlighted the link between label perception and consumer behavior - the manifestation of buying intentions for organic food, that is - the more consumers perceived the label as actionable, the more it became positive their attitude, sense of control and self-reported intention and behavior (Aitken et al, 2020).

Other studies are showing a particular interest regarding health risks associated with specific food products that are not meeting nutritional requirements. Consumers use nutrition labeling for informed choices when selecting healthy diets that lead to healthier outcomes, including reducing the morbidity and mortality associated with poor diets. In the context of their buying process, consumers are using at the purchasing point, both explicit cues (e.g., color, price, and claims) and subtle cues that are communicated by packaging design, such as graphic design, material, and color (Kumar and Kapoor, 2017). Positive attributes and ratings usually occur when consumers associate positive experiences with labels, which leads to improved sales and behavioral intentions resulting from consumer satisfaction (Kim et al, 2013).

Consumers' perceptions and attitudes will mediate between the subjective norm and the behavioral intention. The consumer-conscious subjective norm produces the favorable behavioral intention to read the nutrition label as a result of the positive attitude towards this behavior. Indeed, the provision of nutrition labels at the point of purchase increases consumer satisfaction and purchase intentions

Thereby we can deliberately assume the third hypothesis of the research model as being: (H3): Food Products Labeling Perception positively affects Food Products Buying Decision based on labeling

DOI: 10.24818/18423264/55.2.21.12 
On the Mechanism of the Label Perception: How Does Labeling Change Food Products Customer Behavior?

A specific behavior can evolve into the direction of a loyalty type behavior over time if a couple of endogenous and exogenous factors are manifesting simultaneously. It seems that in the case of food products, perception about labels content and the propensity to gain knowledge about the products can lead to such a behavior. A survey of 789 French customers, which tracked specific consumer behavior for loyal consumers, over the course of a year found that food brands that were accompanied by the Designation of Origin label showed higher levels of loyalty, measured with the polarization index $\varphi$ (phi). (Chrysochou et al, 2012).

Within the process of food products consumption a certain importance can be attached to the perceived risk. The level of the perceived risk can be diminished by the supplementary information that can be obtained by the consumer and new level of experience from the interaction with the products. Certainty regarded as a degree of conviction of a person in relationship with the fact that the evaluation of a certain attribute or a product is the correct one knows a diversified approach in the literature. Knowledge in relation with specific products has been traditionally considered as a multidimensional construct being related in the first place with familiarity and expertise. From this respect product knowledge can have a moderating role in the case of relationship between satisfaction and loyalty for food products. If the consumers have a high degree of objective knowledge this leads to a positive development of loyalty - more knowledge gives birth to stronger attitudes and a more stable behavior (Tuu et al, 2011).

Perceived risk has an indirect effect on loyalty attached to redemption through satisfaction. Studies have also shown that knowledge, consumer access to information reduces the negative effect of risk on satisfaction and thus loyalty - as access to information increases, perceived risk decreases and automatically increases customer satisfaction and potential (Tuu et al, 2011).

Besides the importance of labels, trust is moderating the loyalty for food products. Also the familiarity with the products has an extremely important role as regarding customer loyalty and repurchase intention (Calvo Porral and LevyMangin, 2016).

Authors of a research made on Hungarian consumers, has identified three consumer segments: "price sensitive, loyal to label, label neutral", using discrete choice experiment based on stated preference data, that shows the willingness to pay of the consumers and the importance of labels from the point of view of the intentional behavior (Czine et al, 2020).

It becomes more than evident that we can speak about a direct connection between the behavior regarding decisional process for food products and loyalty of consumers from the point of view of the label interest and active efforts to integrate knowledge about products. Thus we can issue the forth hypothesis of our research as follows: (H4): Food Products Buying Decision based on labeling positively affects Food Products Loyalty based on labeling

After the loyalty development phase, consumers tend to integrate different layers of the behavior and the confirmation of the satisfaction level in the post-

DOI: $10.24818 / 18423264 / 55.2 .21 .12$ 
Ionel Dumitru, Daniel Adrian Gârdan, Carmen Adina Paștiu, Andreea Cipriana Muntean, Iuliana Petronela Gârdan

purchase stage gives them essential motivation to continue the process of searching for information and confirmation of their choices. The statute of a loyal customers comes with different advantages, but most of all, imposes to the consumer to become an informed person and to take further decisions that can confirm former expectations already manifested. Consumers need to be further motivated in order to make again the same type of buying decision process. Visual elements and the volume of information associated with labels in general are becoming important cues that are searched by the loyal customer. A research made on Italian consumers certified the fact that logos regarding the origin trademarks are commonly the main purchasing motivation for consumers, along with knowledge of EU certification labels. Once consumers are becoming accustomed with products they enhance also their interest regarding the labelling issue (Vecchio and Annunziata, 2011). It becomes evident the fact that loyalty based on labeling elicits in a natural way a behavior that has as a main characteristic the continuous interest showed to the labeling issue. Taking account of all of the above we can issue our last hypothesis for the proposed research: (H5): Food Products Loyalty based on labeling positively affects Food Products Labeling Interest

Taking altogether the assumptions made by far, a model that can present in a unitary way the relationship between identified variables will have the following structure as it can be seen in the figure below:

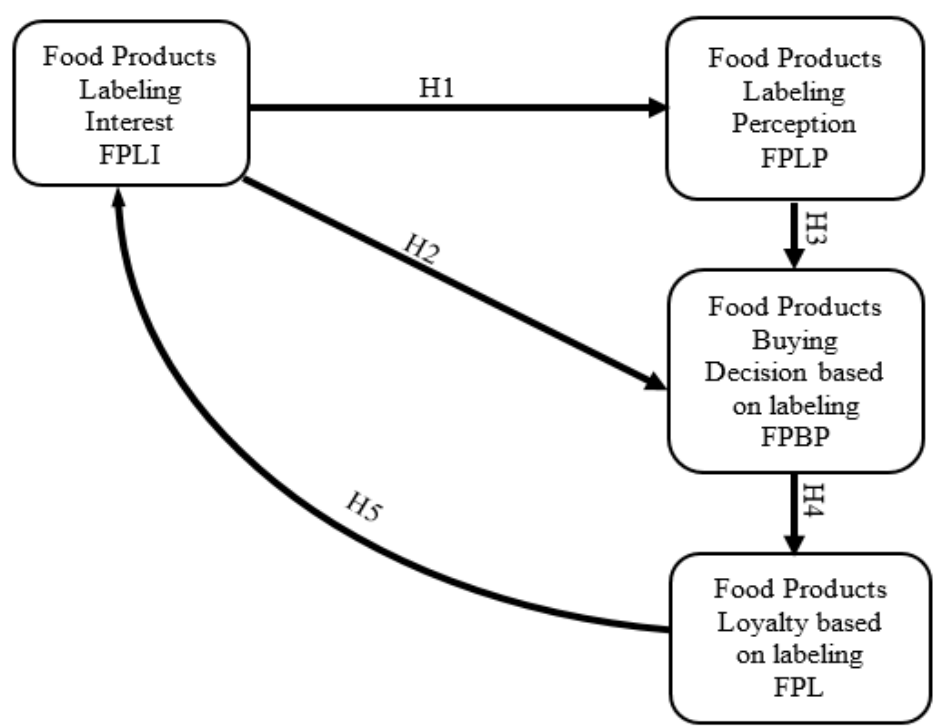

Figure 1. The proposed conceptual model

The advanced hypothesis and the relationship between variables will be tested with the help of analysis of the main components, more precisely using the exploratory factor analysis method. 
On the Mechanism of the Label Perception: How Does Labeling Change Food Products Customer Behavior?

\section{Data and methodology}

As it was highlighted within the literature review presented in the previous section, we have identified hypothesis of the study and the research model illustrated by Figure no 1. Data for this research has been collected using online survey method, through self-administered electronic questionnaires, between January 11, 2021 and February 19, 2021. There have been selected individuals from two large university campuses representative at the national level, from Bucharest and Alba Iulia.1300 individuals have been receiving the questionnaires but only 986 valid questionnaires were returned which means a response rate of $76 \%$. For this study, the responses have been assessed on 5-point Likert type scales ranging from $1=$ strongly disagree, to $5=$ strongly agree. Participants were asked to rate their level of opinion regarding food products buying decision based on labeling. The survey measured food products labeling interest (FPLI), food products labeling perception (FPLP), food products buying decision based on labeling (FPBP), and food products loyalty based on labeling (FPL). The above variables have been measured with 27 items in total, each of them synthetized with the help of literature review presented into the first section of the paper.

Table 1. Conceptual definition of variables

\begin{tabular}{|c|l|l|}
\hline \multicolumn{2}{|c|}{ Variables from the tested model } & \multicolumn{1}{|c|}{ questionnaire } \\
\hline \multirow{2}{*}{$\begin{array}{l}\text { Food products label } \\
\text { interest FPLI }\end{array}$} & $\begin{array}{l}\text { FPLI1 The degree of } \\
\text { interest associated with } \\
\text { food labels }\end{array}$ & Interest in food labels \\
\cline { 2 - 3 } & $\begin{array}{l}\text { FPLI2. Websites of } \\
\text { institutions and / or } \\
\text { organizations in the } \\
\text { field }\end{array}$ & $\begin{array}{l}\text { Websites of institutions and / or } \\
\text { organizations in the field are a } \\
\text { source of information about } \\
\text { food labeling }\end{array}$ \\
\cline { 2 - 3 } & $\begin{array}{l}\text { FPLI3. Magazines and } \\
\text { specialized } \\
\text { publications }\end{array}$ & $\begin{array}{l}\text { Magazines and specialized } \\
\text { publications are a source of } \\
\text { information about food labeling }\end{array}$ \\
\cline { 2 - 3 } & $\begin{array}{l}\text { FPLI4. Personal } \\
\text { sources of information } \\
\text { - Family, friends, } \\
\text { colleagues }\end{array}$ & $\begin{array}{l}\text { Family, friends, colleagues are a } \\
\text { source of information about } \\
\text { food labeling }\end{array}$ \\
\cline { 2 - 3 } & $\begin{array}{l}\text { FPLI5. Events in the } \\
\text { field (workshops, } \\
\text { seminars, conferences, } \\
\text { courses) }\end{array}$ & $\begin{array}{l}\text { Events in the field (workshops, } \\
\text { seminars, conferences, courses) } \\
\text { are a source of information } \\
\text { about food labeling }\end{array}$ \\
\hline
\end{tabular}

DOI: 10.24818/18423264/55.2.21.12 
Ionel Dumitru, Daniel Adrian Gârdan, Carmen Adina Paștiu, Andreea Cipriana Muntean, Iuliana Petronela Gârdan

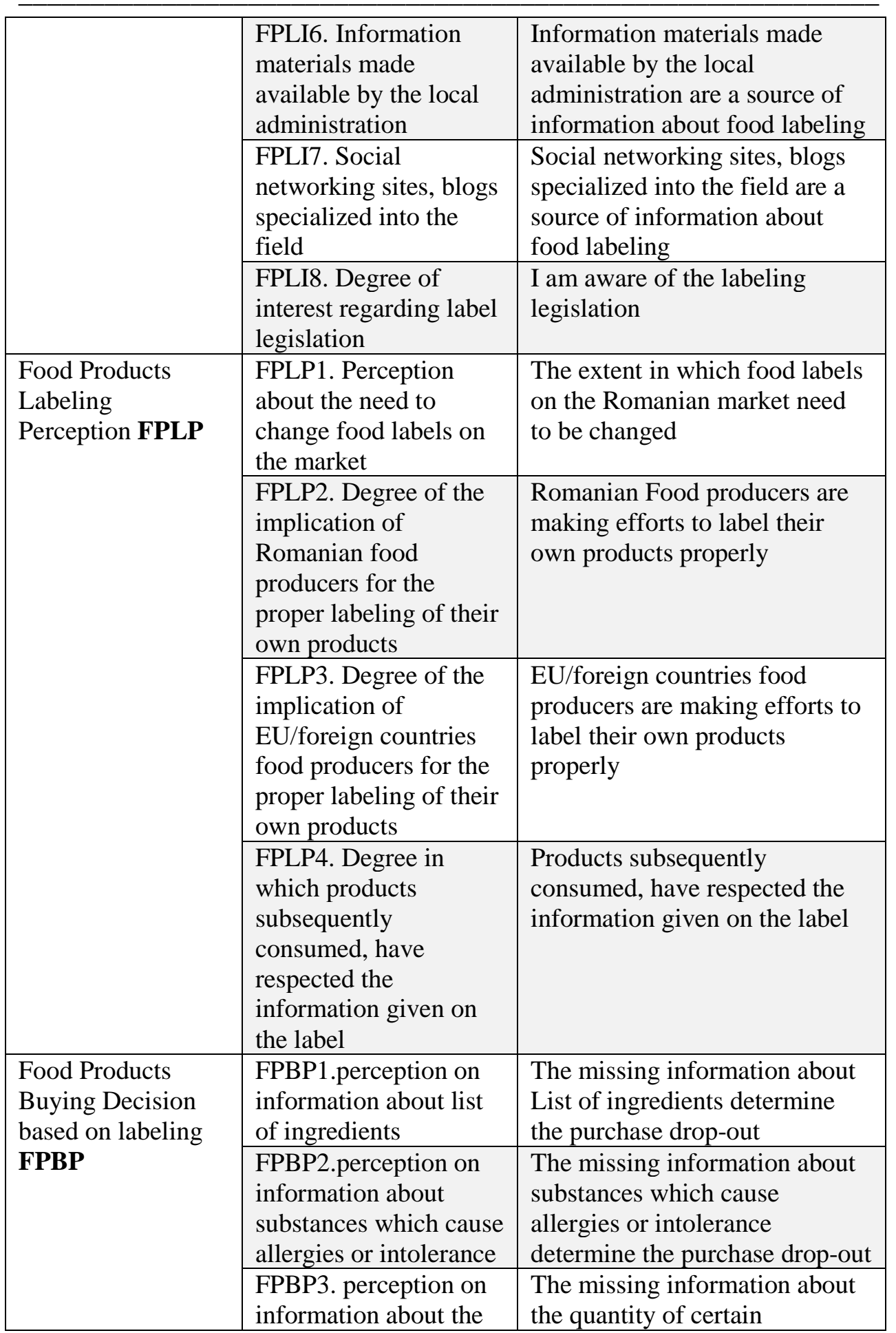

DOI: 10.24818/18423264/55.2.21.12 
On the Mechanism of the Label Perception: How Does Labeling Change Food Products Customer Behavior?

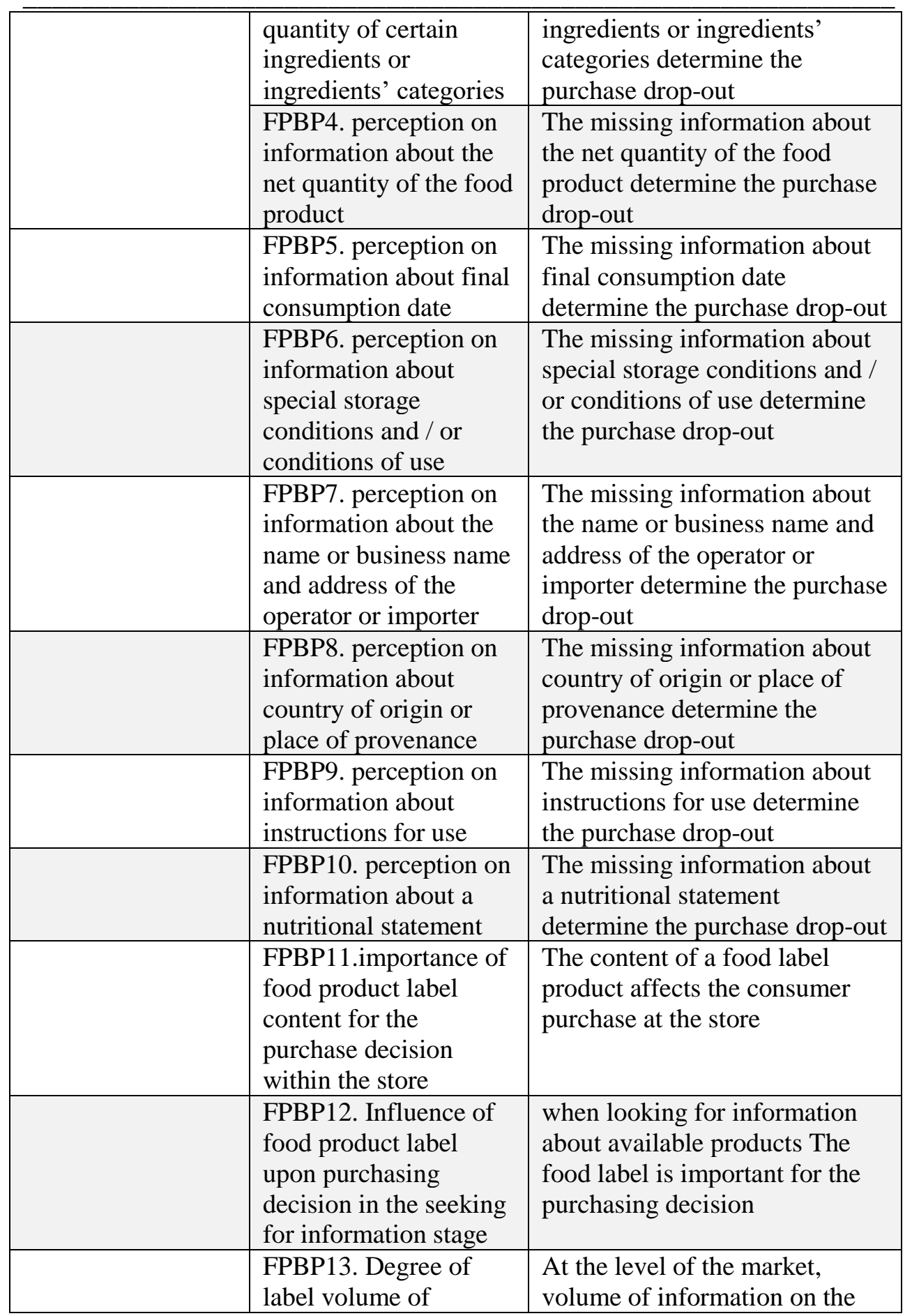

DOI: 10.24818/18423264/55.2.21.12 
Ionel Dumitru, Daniel Adrian Gârdan, Carmen Adina Paștiu, Andreea Cipriana Muntean, Iuliana Petronela Gârdan

\begin{tabular}{|l|l|l|}
\hline & $\begin{array}{l}\text { information necessary } \\
\text { for buying decision }\end{array}$ & $\begin{array}{l}\text { label is sufficient for the } \\
\text { consumer buying decision }\end{array}$ \\
\hline $\begin{array}{l}\text { Food Products } \\
\text { labeling FPL }\end{array}$ & $\begin{array}{l}\text { FPL1. Degree of } \\
\text { satisfaction regarding } \\
\text { the label, associated } \\
\text { with the buying } \\
\text { intention for a certain } \\
\text { food product }\end{array}$ & $\begin{array}{l}\text { Degree of satisfaction with the } \\
\text { label of a food product } \\
\text { determines the buying process } \\
\text { in the future }\end{array}$ \\
\cline { 2 - 3 } & $\begin{array}{l}\text { FPL2. Intention to } \\
\text { purchase products that } \\
\text { are recommended } \\
\text { personal sources, from } \\
\text { the point of view of } \\
\text { labeling }\end{array}$ & $\begin{array}{l}\text { Purchasing of products that are } \\
\text { recommended by friends, } \\
\text { family, from the point of view } \\
\text { of labeling }\end{array}$ \\
\hline
\end{tabular}

All the items were measured with 5-point Likert type scales ranging from $1=$ strongly disagree, to $5=$ strongly agree

At the level of latent dimensions, the factors of the model have been expressed by a different number of composite indicators -8 for FPLI, 4 for FPLP, 13 for FPBP and 2 for FPL, as can be seen in the table no 1

The composite indicators (observed values) attributed to each factor (interest on labeling, labeling perception, food buying decision and food products loyalty) were tested for internal reliabilities.

\section{Results and Discussion}

For the successful management of the model dimensions (interest on labeling, labeling perception, food buying decision and food products loyalty), a procedure called the analysis of the main components was initially used, more precisely the exploratory factor analysis method. The procedure envisages the possibility of reducing the volume of information to be analyzed without actually affecting the final result, by identifying the component variables that could be removed from the analysis. In this sense, the calculation of Cronbach's alpha coefficient was performed, in the case of each factor, in order to be able to measure the internal consistency. Although it is not possible to discuss a specific value that Cronbach's alpha coefficient can have in order to guarantee a high degree of fidelity of the measurements, several researchers suggest that values that are greater than or equal to 0.90 can be considered excellent, while values greater than or equal to 0.80 may be considered good and those greater than or equal to 0.70 are acceptable. (Sheskin, 2020; Knekta et al, 2019). 
On the Mechanism of the Label Perception: How Does Labeling Change Food Products Customer Behavior?

It can be seen, according to the table no 2, that the Cronbach's alpha coefficient value is above 0.90, which means that the fidelity (consistency) of the scales in case of latent variables is confirmed.

Table 2. Values regarding exploratory factor analysis (Values of KaiserMeyer-Olkin test, Bartlett's Test of Sphericity, Cronbach's Alpha coefficient), extracted and retained based on the considered items

\begin{tabular}{|lr|l|}
\hline $\begin{array}{l}\text { Kaiser-Meyer-Olkin Measure of Sampling } \\
\text { Adequacy. }\end{array}$ & .923 \\
\hline Bartlett's Test of Sphericity & \\
& Approx. Chi-Square & 28476.232 \\
df & 351 \\
Sig. & .000 \\
\hline Cronbach's Alpha & .927 \\
\hline
\end{tabular}

In case of Kaiser-Meyer-Olkin (KMO) test, used for the sample adequacy measurement the values are coming close to 0.9 for all the variables meaning that the identified model is very good and the sample size is adequate in order to make the factors analysis (Field, 2013). Within the table it can be seen also that values corresponding to $\mathrm{p}$ and the distribution $\chi^{2}$ are showing that there is no homoscedasticity meaning that the null hypothesis is rejected ( $p<.001$ for each latent variable, and the distribution $\chi 2$ is high) (Field, 2013).

Therefore, the factor analysis can be used because the latent variables determined to start from the initial items are valid in terms of item commonality (Kaiser-Meyer-Olkin test), item sphericity (Bartlett test) and measurement scale consistency (Cronbach's alpha). A confirmatory factor analysis was conducted to assess food products buying decision antecedents and effect on food products loyalty based on labeling, using version 24.0 of the IBM-SPSS AMOS program.

Table 3. Fit indices for the model

\begin{tabular}{|c|c|c|c|c|c|c|c|}
\hline Model & $\mathrm{P}$ & RMR & GFI & RMSEA & PCLOSE & CFI & NFI \\
\hline Research obtained values & .000 & .007 & .898 & .074 & .000 & .940 & .930 \\
\hline Theoretical statistical values & $<.05$ & $<.05$ & $>.90$ & $<.10$ & $<.05$ & $>.95$ & $>.95$ \\
\hline Model & TLI & IFI & RFI & PGFI & PNFI & PCFI & AGFI \\
\hline Research obtained values & .934 & .940 & .922 & .756 & .842 & .852 & .879 \\
\hline Theoretical statistical values & $>.95$ & $>.90$ & $>.90$ & $>.50$ & $>.50$ & $>.50$ & \\
\hline
\end{tabular}

Within the analysis, in the beginning we analyze the goodness of fit, and we point out that indices of the structural model were satisfactory for the analyzed variables (Chi-square $-\mathrm{CMIN}=2022.651, \mathrm{df}=318 ; \mathrm{P}=.000 ; \mathrm{GFI}=.898$; $\mathrm{RMR}=.007$, IFI $=.940$, NFI=.930, TLI=.934, CFI=.940, RMSEA = .074). Comparing the values obtained with the limit values of each index, it can be stated

DOI: 10.24818/18423264/55.2.21.12 
Ionel Dumitru, Daniel Adrian Gârdan, Carmen Adina Paştiu, Andreea Cipriana Muntean, Iuliana Petronela Gârdan

that the proposed model is satisfactory in terms of statistical consistency (Byrne, 2013).

As it can be seen the values within the Table no3 are showing a good fit for all the indices taken into consideration. Cited sources for the identification of theoretical statistical values: (Meyers et al, 2016; Arbuckle, 2016).

Table 4. Standardized direct effect coefficient

\begin{tabular}{|l|l|l|llll|c|}
\hline Hypotheses & Intercept & $\begin{array}{l}\text { Dependent } \\
\text { variables }\end{array}$ & $\beta$ & S.E. & C.R. & P & $\begin{array}{c}\text { Hypothesis } \\
\text { Testing }\end{array}$ \\
\hline H1 & FPLI & FPLP & .015 & .001 & 11.044 & $* * *$ & supported \\
H2 & FPLI & FPBP & .017 & .002 & 9.702 & $* * *$ & supported \\
H3 & FPLP & FPBP & .018 & .002 & 7.621 & $* * *$ & supported \\
H4 & FPBP & FPL & .104 & .007 & 14.632 & $* * *$ & supported \\
H5 & FPL & FPLI & .030 & .003 & 11.003 & $* * *$ & supported \\
\hline
\end{tabular}

Note: ${ }^{* * *} \mathrm{p}<.01$; Statistical significance of parameter estimates test of the statistic critical ratio (C.R.) needs to be $> \pm 1.96$ (Tavakol and Dennick, 2011).

Table no 4 and Figure 2, illustrates that food products buying decision based on labeling antecedents considered within the conceptual model of the research, food products labeling interest and food products labeling perception are valid measurements and have a significant impact on food products buying decision based on labeling.

Table no 4 is showing the degree in which the hypothesis of the model are supported. Thereby the hypothesis 1 is validated, food products labeling interest has a direct positive and significant effect on food products labeling perception $(\beta=.015, \mathrm{p}<.01)$. As the interest of different people in the importance of labeling increases, so does the positive perception of food labeling.

Food products labeling interest has a direct positive and significant effect on food products buying decision based on labeling $(\beta=.017, p<.01)$, which means that also hypothesis 2 is validated. The rise of interest for food products labeling positively affects the behavior of consumers in terms of decisions that count on the products label information.

The third hypothesis advanced a direct positive relationship between perceptions about food products labeling and buying decision. The results $(\beta=.018$, $\mathrm{p}<.01)$ confirm also this hypothesis, perceptions causing a positive modification at the level of buying decision. The effect of food products buying decision based on labeling upon food products loyalty based on labeling was confirmed as being positive and significant also $(\beta=.104, p<.01)$, which is sustaining the validity of hypothesis 4 . As purchasing decisions are increasingly influenced by information that may or may not be found on food labels, products that become preferred are considered by respondents to be products that the consumers tend to return for consumption, with a clear intention of repurchase and loyalty. 
On the Mechanism of the Label Perception: How Does Labeling Change Food Products Customer Behavior?

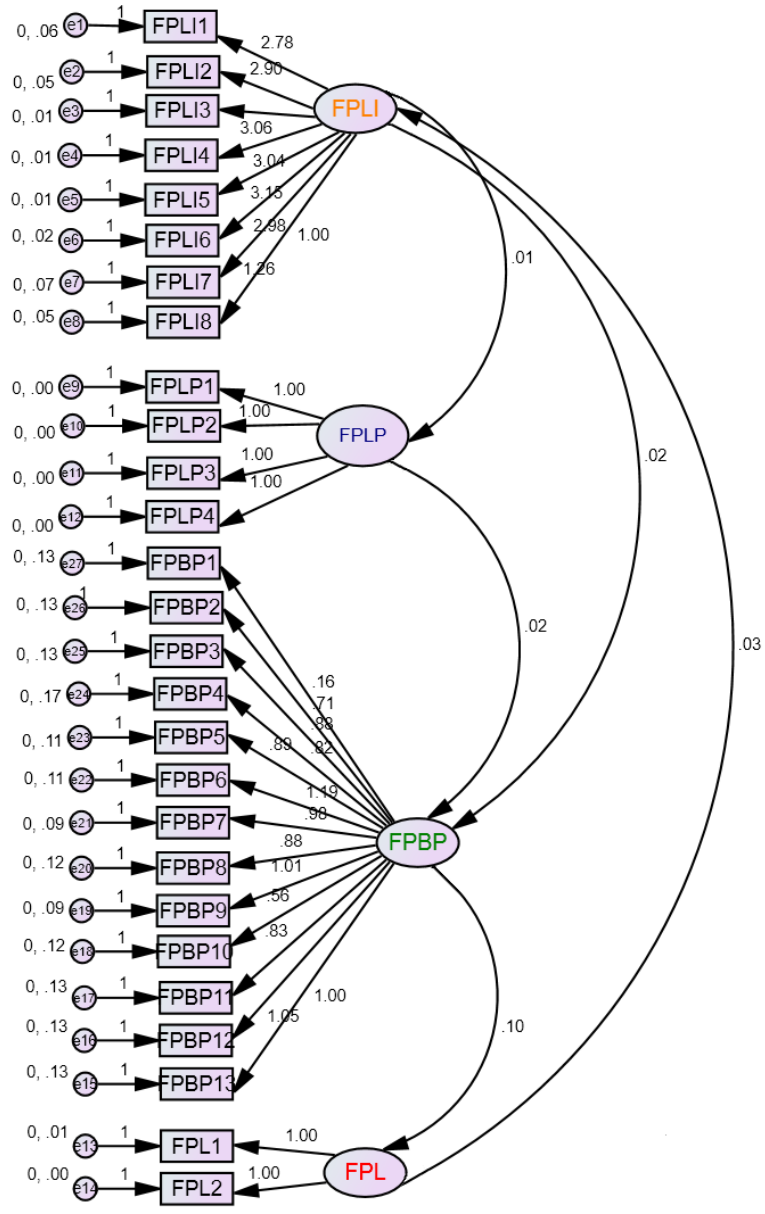

Figure 2. AMOS Graphic with the model results taking account of the hypothesized model and standardized parameter estimates

Finally, the relationship between food products loyalty based on labeling and food products labeling interest is shown to be positive, the effect being also significant $(\beta=.030, \mathrm{p}<.01)$. This supports the validity of hypothesis 5 , and the idea that food products brand that are eliciting loyalty because of the importance and relevance of the label, develop a consumer's attitude that highlights a stronger general interest on labeling, sources of information regarding labeling and labeling legislation content.

The validation of the advanced hypotheses and the model as a whole puts in a new light the statements advanced so far. Also, the causal relationship highlighted can be seen from the perspective of the specificity of consumption concerning the

DOI: 10.24818/18423264/55.2.21.12 
Ionel Dumitru, Daniel Adrian Gârdan, Carmen Adina Paștiu, Andreea Cipriana Muntean, Iuliana Petronela Gârdan

analyzed products. Our research took into account the perception regarding food products labeling, and the specific decisional buying process for this type of products. Due to the important changes at the level of consumption culture regarding food products, these type of products have become more and more dependent by the information delivered with the help of labels and other informational elements

\section{Conclusions}

The results of the analysis are showing stronger effects between Food Products Buying Decision based on labeling and Food Products Loyalty based on labeling and respectively Food Products Labeling Interest and Food Products Labeling Perception, along with Food Products Loyalty based on labeling and Food Products Labeling Interest, in comparison with the rest of the effects between variables.

These results support the idea advanced that in the case of Romanian consumers and the specific context of consumption for the considered products, the decisional process based on labeling represents a real driver for satisfaction and trust.

As limitations of the research it is important to remember that the sample was composed mainly of people from university campuses - students and master students, and among them, a more significant proportion of respondents have been women who denote a higher propensity to respond among them.

The research should be extended in the sense of sampling an equilibrated amount of females and males respondents and a greater diversity of consumers from different social or occupational layers to verify if the proposed model can be extended accordingly to different consumption backgrounds.

\section{REFERENCES}

[1] Aitken, R., Watkins, L., Williams, J., Kean, A. (2020), The Positive Role of Labelling on Consumers' Perceived Behavioural Control and Intention to Purchase Organic Food. Journal of Cleaner Production, 255, 120334;

[2] Arbuckle, J.L. (2016), IBM SPSS Amos 24 User's Guide, Amos Development Corporation; New York: IBM Corp;

[3] Asioli, D., Aschemann-Witzel, J., Caputo, V., Vecchio, R., Annunziata, A., Næs, T., Varela, P. (2017), Making Sense of the "Clean Label” Trends: A Review of Consumer Food Choice Behavior and Discussion of Industry Implications. Food Research International, 99, 58-71; 
On the Mechanism of the Label Perception: How Does Labeling Change Food Products Customer Behavior?

[4] Byrne, B.M. (2013), Structural Equation Modeling with Mplus: Basic Concepts, Applications, and Programming. New York: Routledge, Taylor \& Francis Group;

[5] Calvo Porral, C., Levy-Mangin, J.-P. (2016), Food Private Label Brands: The Role of Consumer Trust on Loyalty and Purchase Intention; British Food Journal, 118(3), 679-696;

[6] Campos, S., Doxey, J., Hammond, D. (2011), Nutrition Labels on PrePackaged Foods: A Systematic Review. Public Health Nutrition, 14(8), 14961506;

[7] Chrysochou, P., Krystallis, A., Giraud, G. (2012), Quality Assurance Labels as Drivers of Customer Loyalty in the Case of Traditional Food Products. Food quality and preference, 25(2), 156-162;

[8] Czine, P., Török, Á., Petö, K., Horváth, P., Balogh, P. (2020), The Impact of the Food Labeling and Other Factors on Consumer Preferences Using Discrete Choice Modeling - The Example of Traditional Pork Sausage. Nutrients, 12(6), 1-18;

[9] Czyżewski, B., Stępień, S., \& Maican, S. (2018), The role of the Rural Development Programme (RDP) in creating growth in the agricultural sector. The case of countries from East-Central Europe. 7th International Scientific Conference on Determinants of Regional Development, Pila, Poland, 22-42; [10] Field, A. (2013), Discovering Statistics Using IBM SPSS Statistics, 4th ed, London: SAGE Publications Ltd;

[11] Galati, A., Schifani, G., Crescimanno, M., Migliore, G. (2019), Natural Wine" Consumers and Interest in Label Information: An Analysis of Willingness to Pay in a New Italian Wine Market Segment. Journal of Cleaner Production, 227, 405-413;

[12] Hemmerling, S., Hamm, U., Spiller, A. (2015), Consumption Behaviour Regarding Organic Food from a Marketing Perspective - A Literature Review. Organic Agriculture, 5(4), 277-313;

[13] Ingrassia, M., Bacarella, S., Columba, P., Altamore, L., Chironi, S. (2017), Traceability and Labelling of Food Products from the Consumer Perspective. Chemical Engineering Transactions, 58, 865-870;

[14] Kim, E., Ham, S., Yang, I.S., Choi, J. G. (2013), The Roles of Attitude, Subjective Norm, and Perceived Behavioral Control in the Formation of Consumers' Behavioral Intentions to Read Menu Labels in the Restaurant Industry. International Journal of Hospitality Management, 35, 203-213; [15] Knekta, E., Runyon, C., Eddy, S. (2019), One Size Doesn't Fit All: Using Factor Analysis to Gather Validity Evidence when Using Surveys in Your Research. CBE-Life Sciences Education, Am. Soc. Cell. Biol., 18(1), 1-17; [16] Kumar, N., Kapoor, S., (2017), Do Labels Influence Purchase Decisions of Food Products? Study of Young Consumers of an Emerging Market. British Food Journal, 119(2), 218 - 229;

DOI: 10.24818/18423264/55.2.21.12 
Ionel Dumitru, Daniel Adrian Gârdan, Carmen Adina Paștiu, Andreea Cipriana Muntean, Iuliana Petronela Gârdan

[17] Meyers, L.S., Gamst, G., Guarino, A.J. (2016), Applied Multivariate Research: Design and Interpretation, 3rd ed., Los Angeles: Sage Publications; [18] Moreira, M.J., García-Díez, J., de Almeida, J.M.M.M., Saraiva, C. (2019), Evaluation of Food Labelling Usefulness for Consumers. International Journal of Consumer Studies, 43(4), 327-334;

[19] Reveiu, A., Smeureanu, I., Dardala, M., Kanala, R. (2015), Modelling Domestic Lighting Energy Consumption in Romania by Integrating Consumers Behavior. Procedia Computer Science, 52, 812-818;

[20] Rupprecht, C.D., Fujiyoshi, L., McGreevy, S.R., Tayasu, I. (2020), Trust me? Consumer Trust in Expert Information on Food Product Labels. Food and Chemical Toxicology, 137, 1-9;

[21] Sheskin, D.J. (2020), Handbook of Parametric and Nonparametric Statistical Procedures. Boca Raton, FL: CRC Press, Taylor \& Francis Group, 1615-1635;

[22] Solomon, M.R. (2013), Consumer Behaviour: Buying, Having, and Being, 10th global edition. New Jersey: Prentice-Hall;

[23] Tavakol, M., Dennick, R. (2011), Making Sense of Cronbach's Alpha, International Journal of Medical Education, 2, 53-55;

[24] Türkeș, M.C., Căpușneanu, S., Topor, D.I., Staraș, A.I., Hint, M.Ș., Stoenica, L.F. (2020), Motivations for the Use of IoT Solutions by Company Managers in the Digital Age: A Romanian Case. Applied Sciences, 10(19), 1-28; [25] Tuu, H.H., Olsen, S.O., Linh, P.T.T. (2011), The Moderator Effects of Perceived Risk, Objective Knowledge and Certainty in the Satisfaction-Loyalty Relationship. Journal of Consumer Marketing, 28(5), 363-375;

[26] Vecchio, R., Annunziata, A. (2011), The role of PDO/PGI Labelling in Italian Consumers' Food Choices. Agricultural Economics Review, 12(2), 80-98; [27] Wang, J., Tao, J., Chu, M. (2020), Behind the Label: Chinese Consumers' Trust in Food Certification and the Effect of Perceived Quality on Purchase Intention. Food Control, 108, 106825. 